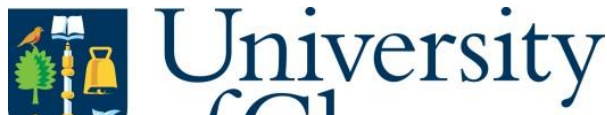 of Glasgow
}

He, W., Donaldson, C.R., Zhang, L., McElhinney, P. , Garner, J., Ronald, K., Cross, A.W. and Phelps, A.D.R. (2021) Measurement of a W-band Gyro-TWA Experiment Based on a Helically Corrugated Interaction Region. In: 2017 Eighteenth International Vacuum Electronics Conference (IVEC), London, UK, 24-26 April 2017, ISBN 9781509059171 (doi:10.1109/IVEC.2017.8289637)

The material cannot be used for any other purpose without further permission of the publisher and is for private use only.

There may be differences between this version and the published version. You are advised to consult the publisher's version if you wish to cite from it.

\section{http://eprints.gla.ac.uk/233687/}

Deposited on 04 March 2021

Enlighten - Research publications by members of the University of Glasgow http://eprints.gla.ac.uk 


\title{
Measurement of a W-band gyro-TWA experiment based on a helically corrugated interaction region
}

\author{
W. He, C. R. Donaldson, L. Zhang, P. McElhinney, J. Garner, K. Ronald, A. W. Cross and A. D. R. Phelps \\ Department of Physics, SUPA, University of Strathclyde \\ Glasgow, Scotland, UK, G4 0NG \\ w.he@strath.ac.uk
}

\begin{abstract}
Measurements of an upgraded W-band gyro-TWA with a helically corrugated waveguide and a cusp electron gun are presented. With upgraded input coupler and output systems a gain of $\sim 37 \mathrm{~dB}$ was measured from the experiment with a maximum output power of over $2 \mathrm{~kW}$. The amplification from the gyro-TWA was measured in the frequency range of $90 \mathrm{GHz}$ to $96 \mathrm{GHz}$.
\end{abstract}

Keywords-gyrotron traveling-wave amplifier; gyro-TWA; helically corrugated interaction region; cusp electron gun.

\section{INTRODUCTION}

The Gyrotron traveling wave amplifier (Gyro-TWA) has promising applications in areas such as RADAR, telecommunications, plasma diagnostics and electron spin resonance spectroscopy due to its excellent combination of high power and broad bandwidth. In the past gyro-TWAs and gyrotron backward wave oscillators based on helically corrugated interaction regions (HCIR) have achieved unprecedented power-bandwidth performance [1-4]. A Wband gyro-TWA has been experimentally studied at Strathclyde University. The gyro-TWA is designed to be driven by a $40 \mathrm{kV}, 1.5 \mathrm{~A}$ annular shaped large-orbit electron beam.

A photo of the W-band gyro-TWA is shown in Fig. 1. The gyro-TWA includes magnetic coils, a cusp electron gun, an input coupling system, an elliptical converter, a HCIR and an output system [5-12].

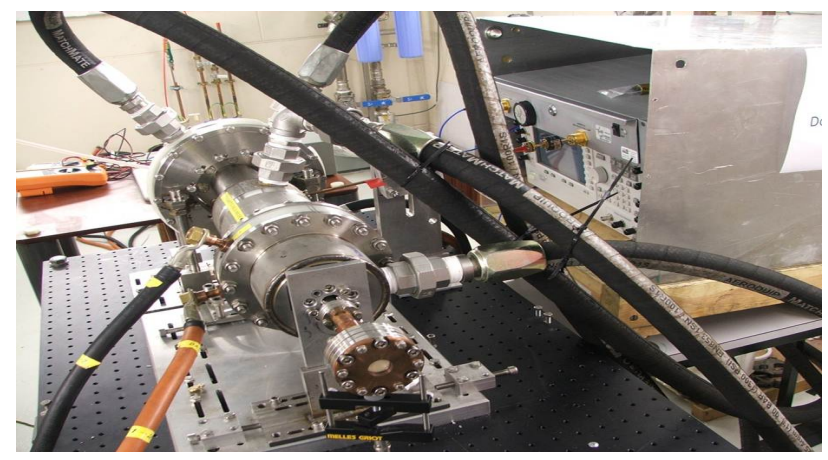

Fig. 1. A photo of the W-band gyro-TWA.

A 1.5 W Quinstar signal source operating over the range 90-96 GHz was fed into the gyro-TWA using the input coupling system which consisted of an in-band pillbox window, waveguide bends and a Bragg reflector. The input

This work was supported by the Engineering and Physical Sciences Research Council (EPSRC) U.K. under Research Grants EP/M008622/1 and EP/K029746/1, and by the Science and Technology Facilities Council (STFC) U.K. under Research Grants ST/K006673/1 and ST/N002326/1. wave was converted into a circularly polarization wave from a linearly polarized wave by the elliptical converter before reaching the HCIR. The eigenwave in the HCIR could resonantly interact with the axis-encircling electron beam generated from the cusp electron gun, which resulted in transfer of the electron beam power into microwave power and hence the amplification of the input microwave signal.

\section{THE PRINCIPLE}

To increase the bandwidth of the amplifier a three-fold HCIR has been used. The resonant coupling of the $\mathrm{TE}_{21}$ mode and the first spatial harmonic of the $\mathrm{TE}_{11}$ mode in the HCIR gives rise to an "ideal" eigenwave for the amplifier. The eigenwave, which has an almost constant value of group velocity over a wide frequency band in the region of small axial wave numbers [7], can be readily matched by the dispersion line of an electron cyclotron mode or its harmonics allowing broadband microwave amplification to be achieved in a gyrotron traveling wave amplifier.

The large-orbit electron beam, generated from a cusp electron gun [5], is ideal for harmonic operation of gyrodevices as the mode selectivity nature of such a beam requires that the harmonic number is equal to the azimuthal index of a waveguide mode for effective beam wave coupling, which leads to a reduced possibility of parasitic oscillations.

A $\mathrm{T}$-junction was used to convert the $\mathrm{TE}_{10}$ mode in rectangular waveguide into the $\mathrm{TE}_{11}$ mode in circular waveguide. To enhance the coupling coefficient, a broadband reflector was used. The performance of the T-junction with the Bragg reflector was measured by a $\mathrm{W}$-band vector network analyzer (VNA) and an average $1.0 \mathrm{~dB}$ transmission loss was measured.

\section{THE RESULTS}

The input coupler is required to have a good transmission coefficient and sufficient bandwidth for the operation of the gyro-TWA $[6,10,11]$. A Bragg reflector [12] and the pillbox window were optimized for microwave transmission and broad bandwidth. It could be easily connected to the input source with standard WR-10 waveguide. The overall transmission loss of the whole input coupler system was calibrated by a W-band VNA to be about $2 \mathrm{~dB}$ which included a $0.6 \mathrm{~dB}$ loss from the pillbox window and $1.4 \mathrm{~dB}$ loss from the rectangular waveguides. 
The output system of the wideband gyro-TWA consisted of a high performance profiled sine squared/parallel corrugated horn integrated with a broadband multi-layer window. The major design requirements were that the horn/window combination must have an input reflection coefficient lower than $-30 \mathrm{~dB}$ over the $10 \mathrm{GHz}$ bandwidth of the gyro-TWA, provide a high quality output beam pattern, and operate under ultra-high vacuum conditions. The coupler would convert a circular waveguide $\mathrm{TE}_{11}$ mode into the free space Laguerre Gaussian $\mathrm{LG}_{00}$ mode over the frequency band of $90-100 \mathrm{GHz}$ with a measured reflection coefficient of between -30 and $-40 \mathrm{~dB}$, and a high Gaussian coupling efficiency of over $99 \%$ at $94 \mathrm{GHz}$.

Far-field radiation measurements of the co-polar E-plane, $\mathrm{H}$-plane and the cross-polar D-plane components were carried out at $94 \mathrm{GHz}$ and are shown in Figure 2. Low sidelobe levels of $-35 \mathrm{~dB}$ were in excellent agreement with simulations and demonstrate that the addition of the window has a negligible effect on the antenna pattern. The cross-polar measurement was also in good agreement with the simulations, with a maximum of $-31.8 \mathrm{~dB}$, compared to a simulated maximum of $-34.2 \mathrm{~dB}$. The maximum power was measured to be $2 \mathrm{~kW}$ at $94 \mathrm{GHz}$ which corresponded to an amplification gain of 37 $\mathrm{dB}$. Output power of the gyro-TWA as a function of the frequency was also measured. A typical microwave pulse observed through a W-band crystal detector is shown in Fig. 3.

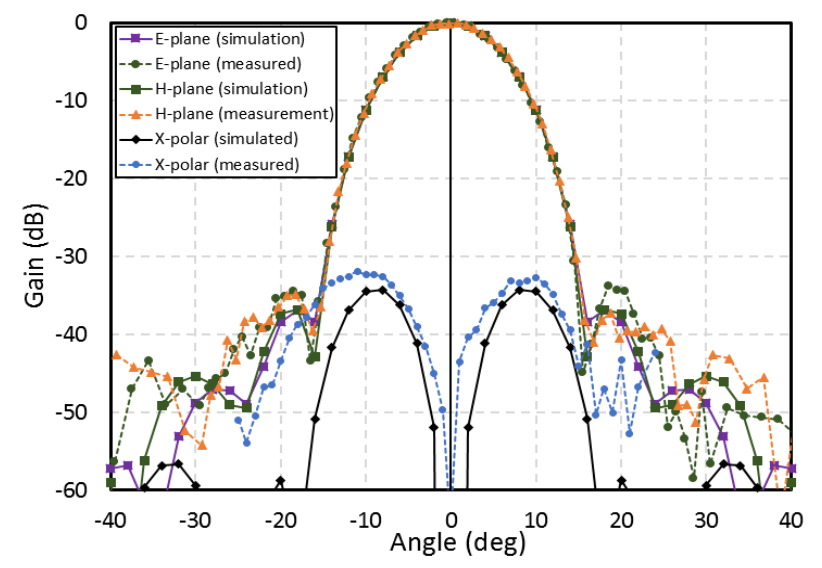

Fig 2. The measured and simulated co-polar E-plane, H-plane and crosspolar D-plane scans of the output coupler with window at $94 \mathrm{GHz}$.

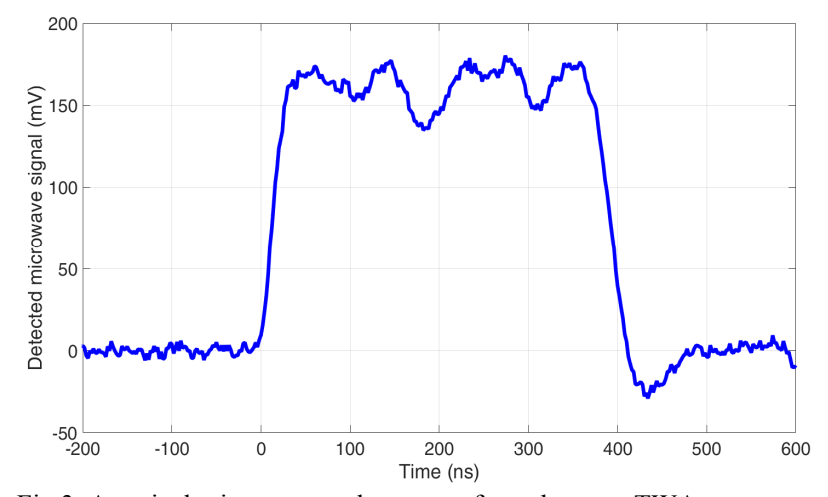

Fig 3. A typical microwave pulse output from the gyro-TWA.

\section{ACKNOWLEDGMENTS}

The authors would like to thank Dr. P. Huggard, Mr M. Beardsley and Mr. P. Hiscock of the Millimetre Wave Technology Group at the STFC Rutherford Appleton Laboratory, UK for the construction of the HCIR.

\section{REFERENCES}

[1] V. L. Bratman, A. W. Cross, G. G. Denisov, W. He, A. D. R. Phelps, K. Ronald, S. V. Samsonov, C. G. Whyte, and A. R. Young, "High-gain wide-band gyrotron traveling wave amplifier with a helically corrugated waveguide," Phys. Rev. Lett., vol. 84, pp. 2746-2749, March 2000.

[2] A. W. Cross, W. He, A. D. R. Phelps et al., "Helically corrugated waveguide gyrotron traveling wave amplifier using a thermionic cathode electron gun," Appl. Phys. Lett., vol. 90, art. no. 253501, June 2007.

[3] W. He, K. Ronald, A. R. Young, A. W. Cross, A. D. R. Phelps, C. G. Whyte, E. G. Rafferty, J. Thomson, C. W. Robertson, D. C. Speirs, S. V. Samsonov, V. L. Bratman, and G. G. Denisov, "Gyro-BWO experiments using a helical interaction waveguide," IEEE Trans. Electron Devices, vol. 52, pp. 839-844, May 2005.

[4] W. He, C. R. Donaldson, L. Zhang, K. Ronald, P. McElhinney, and A. W. Cross, "High power wideband gyrotron backward wave oscillator operating towards the terahertz region," Phys. Rev. Lett., vol. 110, art. no. 165101, April 2013.

[5] C. R. Donaldson, W. He, A.W. Cross, F. Li, et al., "A cusp electron gun for millimeter wave gyro-devices", Appl. Phys. Lett., vol. 96, art. no. 141501, April 2010.

[6] L. Zhang, W. He, C. R. Donaldson, J. R. Garner, P. McElhinney, and A. W. Cross, "Design and measurement of a broadband sidewall coupler for a W-band gyro-TWA," IEEE Trans. Microw. Theory Techn., vol. 63, no. 10, pp. 3183-3190, Oct. 2015.

[7] L. Zhang et al., "Multi-mode coupling wave theory for helically corrugated waveguide," IEEE Trans. Microw. Theory Techn., vol. 60, no. 1, pp. 1-7, Jan. 2012.

[8] P. McElhinney, C.R. Donaldson, L. Zhang, and W. He, "A high directivity broadband corrugated horn for W-band gyro-devices, "IEEE Trans. Antennas Propag., vol. 61, pp. 1453-1456, March 2013.

[9] C. R. Donaldson, P. McElhinney, L. Zhang, and W. He, "Wide-band HE11 mode terahertz wave windows for gyro-amplifiers, "IEEE Trans. THz Sci. Technol., vol. 6, pp. 108-112, Jan. 2016.

[10] J. R. Garner, L. Zhang, C. R. Donaldson, A. W. Cross, and W. He, "Design study of a fundamental mode input coupler for a $372-\mathrm{GHz}$ gyro-TWA I: Rectangular-to-circular coupling methods," IEEE Trans. Electron Devices, vol. 63, no. 1, pp. 497-503, Jan. 2016.

[11] J. R. Garner, L. Zhang, C. R. Donaldson, A. W. Cross, and W. He, "Design Study of a 372-GHz High Order Mode Input Coupler," IEEE Trans. Electron Devices, vol. 63, no. 8, pp. 3284-3290, Aug. 2016.

[12] L. Zhang, W. He, C. R. Donaldson, and A. W. Cross, "Bandwidth Study of the Microwave Reflectors with Rectangular Corrugations," $J$. Infrared Milli. Terahz. Waves, vol. 37, pp. 846-856, 2016. 